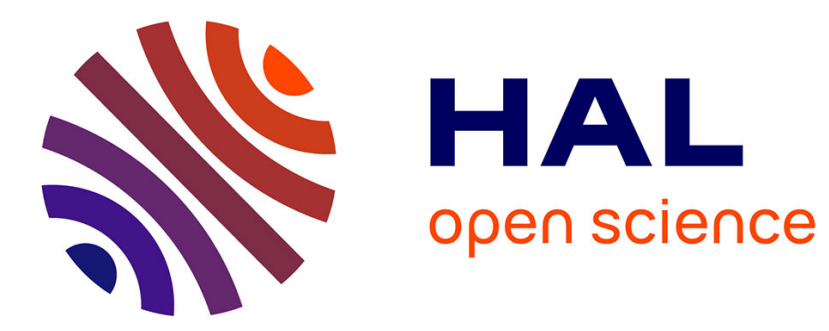

\title{
Perfumers' expertise induces structural reorganization in olfactory brain regions.
}

Chantal Delon-Martin, Jane Plailly, Pierre Fonlupt, Alexandra Veyrac, Jean-Pierre Royet

\section{To cite this version:}

Chantal Delon-Martin, Jane Plailly, Pierre Fonlupt, Alexandra Veyrac, Jean-Pierre Royet. Perfumers' expertise induces structural reorganization in olfactory brain regions.: Structural plasticity in perfumers. NeuroImage, 2013, 68, pp.55-62. 10.1016/j.neuroimage.2012.11.044 . inserm-00783725

\section{HAL Id: inserm-00783725 https://www.hal.inserm.fr/inserm-00783725}

Submitted on 1 Feb 2013

HAL is a multi-disciplinary open access archive for the deposit and dissemination of scientific research documents, whether they are published or not. The documents may come from teaching and research institutions in France or abroad, or from public or private research centers.
L'archive ouverte pluridisciplinaire HAL, est destinée au dépôt et à la diffusion de documents scientifiques de niveau recherche, publiés ou non, émanant des établissements d'enseignement et de recherche français ou étrangers, des laboratoires publics ou privés. 


\title{
Perfumers' expertise induces structural reorganization in olfactory brain regions
}

\author{
Chantal Delon-Martin $^{a, b,{ }^{*}}$, Jane Plailly ${ }^{c}$, Pierre Fonlupt ${ }^{d}$, Alexandra Veyrac ${ }^{e}$, Jean- \\ Pierre Royet ${ }^{\mathrm{c}, *}$
}

a INSERM U836, Institut des Neurosciences, Equipe Neuroimagerie et Perfusion Cérébrale, Grenoble F-38043, France. E-mail: chantal.delon@ujf-grenoble.fr

${ }^{\mathrm{b}}$ Université Joseph Fourier, Grenoble Institut des Neurosciences, BP 170, Grenoble cedex 9, F38043, France.

${ }^{c}$ Olfaction: from coding to memory team, INSERM U1028, CNRS UMR 5292 - Université Lyon 1, Lyon F-69366, France. E-mail: plailly@olfac.univ-lyon1.fr, royet@olfac.univ-lyon1.fr

${ }^{\mathrm{d}}$ Brain, Dynamics and Cognition team, INSERM U1028, CNRS UMR 5292 - Université Lyon 1, Bron F-69675, France. E-mail: pierre.fonlupt@inserm.fr

${ }^{\mathrm{e}}$ Centre de Neurosciences Paris-Sud, CNRS UMR 8195, Université Paris-Sud XI, Orsay, F-91405, France. E-mail: alexandra.veyrac@u-psud.fr

Abbreviated Title:

* Corresponding Author: Chantal Delon-Martin

INSERM U836, Institut des Neurosciences, Equipe Neuroimagerie et Perfusion Cérébrale, BP 170, Grenoble cedex 9, F-38043, France Phone: +33 (0)4 56520602 Fax: +33 (0)4 56520598 chantal.delon@ujf-grenoble.fr

** Corresponding Author: Jean-Pierre Royet

Olfaction: from coding to memory team,

INSERM U1028, CNRS UMR 5292

50, Avenue Tony Garnier

Université Lyon 1, Lyon F-69366, France, Phone: +33 (0)4 37287495

Fax: +33(0)437287601 royet@olfac.univ-lyon1.fr 


\section{ABSTRACT}

The human brain's ability to adapt to environmental changes is obvious in specific sensory domains of experts, and olfaction is one of the least investigated senses. As we have previously demonstrated that olfactory expertise is related to functional brain modifications, we investigated here whether olfactory expertise is also coupled with structural changes. We used voxel-based morphometry to compare the gray-matter volume in student and professional perfumers, as well as untrained control subjects, and accounted for all methodological improvements that have been recently developed to limit possible errors associated with image processing. In all perfumers, we detected an increase in gray-matter volume in the bilateral gyrus rectus/medial orbital gyrus (GR/MOG), an orbitofrontal area that surrounds the olfactory sulcus. In addition, gray-matter volume in the anterior PC and left GR/MOG was positively correlated with experience in professional perfumers. We concluded that the acute olfactory knowledge acquired through extensive olfactory training leads to the structural reorganization of olfactory brain areas.

\section{Keywords}

Olfaction, Perfumer, Expertise, Gray-matter volume, Voxel-based morphometry, Structural reorganization 


\section{Introduction}

Numerous studies in humans have indicated that functional and anatomical modifications occur in the brain because of learning and training. In experts with enhanced visual, auditory or motor skills, such as musicians and athletes, greater performance is associated with functional and structural brain changes in modality-specific brain areas, which supports the view that brain reorganization is associated with expertise.

What about olfactory expertise? Could the brain reorganization observed with expertise in other modalities be generalized to olfaction? This question has been addressed only once before, probably because human olfactory abilities are less essential for survival than other senses and are more poorly developed compared to those of other mammals, and because olfactory experts, such as perfumers, are rare. While exploring brain process related to odor mental imagery, we observed an expertise-dependent functional reorganization in olfactory and mnesic brain areas, such as the primary olfactory (piriform) cortex (PC) and hippocampus, which was concomitant to enhanced behavioral performances with expertise. To the best of our knowledge, brain structural reorganization in olfactory expert has never been investigated. However, focusing on alterations of olfactory processes, several studies have shown gray matter (GM) atrophy in olfactory-related areas in patients suffering from anosmia, or hyposmia because of peripheral dysfunction or neurological disease . Whether subjects with olfactory expertise present modifications of GM volume in olfactory areas is an open question.

Computational morphometry tools allow for investigation of structural brain changes related to development, learning, expertise and pathology . The voxel-based morphometry (VBM) technique is broadly used and remains an active field of methodological research . Several pitfalls in image preprocessing, including inter-individual misregistration and errors in the segmentation procedure, skull-stripping and bias correction, and bias induced by improper templates and priors, are the subjects of vigorous debate in the neuroimaging community. However, methodological 
improvements have recently been developed that may limit possible errors . First, the segmentation algorithm can include bias correction, and can now model not only brain tissues but also non-brain tissues. This allows removing potential contamination from soft tissues outside the brain, large vessels and skull. Second, a study-specific template can be created. Third, algorithms for diffeomorphic image registration with a high number of degrees of freedom can be employed to obtain accurate registration of each individual brain with a given template. In particular, the algorithm for "Diffeomorphic Anatomical Registration using Exponentiated Lie algebra" better known under the DARTEL acronym is considered as being among the best algorithms available . Fourth, the segmentation and the spatial registration procedure can be combined in a unified approach to improve preprocessing steps . A recent VBM test-retest study showed that when using all above-mentioned improvements as implemented in Statistical Parametric Mapping 8 (SPM8) using DARTEL, this permits to avoid obtaining most of the false positives . Fifth, voxels which feature low effect-size and very low variance can be artifactually significant . In order to reduce false positives, the newest SPM8 release (v.4010, April 04, 2011) includes a scheme to force such voxels to have low significance in VBM statistical analysis .

In the current study, we used structural magnetic resonance imaging (MRI) and the VBM pipeline with DARTEL in statistical parametric mapping (SPM8) software. We scanned 14 perfumers renowned for creating perfumes, 13 students from an international school of perfumery and 21 control subjects. We took advantage of variability in length of expertise in professional perfumers to identify structural brain reorganization that is associated with experience under the hypothesis that intensive olfactory training may lead to increased GM volumes in olfactory- and memory-related areas. 


\section{Materials and Methods}

Subjects

Forty-eight healthy right-handed subjects participated in our study. The perfumers' group included 13 young experts (YE; 3 men; mean age, 23 years; range, 21-26 years) who were students at an international school of perfumery (Institut Supérieur International de la Parfumerie, de la Cosmétique et de l'Aromatique, Versailles, France), and 14 older experts (OE; 10 men; mean age, 42 years; range, 29-59 years) who were professionals known for creating perfumes. While the YE had been trained for 2 years at most as part of their education, all OE had 5-35 years of careerrelevant business experience. The control group was composed of 21 untrained subjects, including 8 young controls (YC; 2 men; mean age, 25 years; range, 24-28 years) and 13 older controls (OC; 6 men; mean age, 40 years; range, 30-55 years). Subjects from both groups were matched in age

$\left(F_{(1,47)}=0.10, p=0.712\right)$ and gender $\left(\chi^{2}=0.34, p=0.560\right)$.

The exclusion criteria were rhinal disorders (e.g., a history of nasal-sinus surgery), pregnancy, ferrous implants (e.g., pacemakers and cochlear implants), claustrophobia, or any neurological disease. This study was conducted according to French regulations on biomedical experiments using healthy volunteers and according to the principles outlined in the Declaration of Helsinki. All subjects gave written informed consent, as required by the local Institutional Review Board.

\section{Structural Data Acquisition}

All structural images were acquired on a Philips NT 1.5-Tesla MRI scanner (Philips Medical Systems, Best, Netherlands) with a birdcage head coil. The high resolution anatomical images of the olfactory experts were acquired during an fMRI study investigating the neural substrates of olfactory imagery and on controls during a visual retinotopy protocol that was conducted on the same scanner with the same sequence and at the same period of time as the scanning of olfactory experts . A high-resolution $\left(1 \mathrm{~mm}^{3}\right)$ structural image was acquired with the same sequence for all 
subjects using a 3-dimensional, T1-weighted gradient echo sequence [repetition time $=23.7 \mathrm{~ms}$, echo time $=6.9 \mathrm{~ms}$, flip angle $=28^{\circ}$, number of accumulations $\left.=2\right]$. This acquisition sequence type has been shown to be particularly efficient when studying the inner part of the cortex .

\section{Structural Data Preprocessing}

We processed and analyzed the structural data using a VBM approach and SPM8 software (www.fil.ion.ucl.ac.uk/spm/software/spm8/) with default parameters.

For the first step, each individual image was segmented using the 'New Segment' tool provided with the DARTEL toolbox . This procedure performs segmentation and spatial normalization in a unified generative model based on a mixture of Gaussians with spatial priors and bias correction. In addition, the algorithm includes non-brain tissues (dura, scalp and large vessels), which ensures that the calculation of GM images is uncontaminated by either the skull or large veins. This approach permits to skip the bias correction and skull-stripping procedure, which improves VBM preprocessing .

In a second step, a study-specific template was calculated from all subjects' GM and white matter (WM) images using the DARTEL framework . This diffeomorphic registration algorithm iteratively estimates the non-linear deformations that best align the GM and WM images together, which provides a common study-specific template and deformation field that parameterizes the deformations for each subject's image.

In a third step, to spatially normalize the images to the Montreal Neurological Institute (MNI) standard brain, we calculated the affine registration that realigned our study-specific template generated using DARTEL with the GM tissue probability map in the MNI space. For each subject, we applied a combination of the deformation field and affine registration to the GM and structural images of each individual. The spatially normalized GM segmented images were further modulated with the Jacobian of the deformation field to adjust for the resulting volume changes and derive GM volume-related images. The realigned structural images of all subjects were averaged for display purposes. 
In a fourth step, to improve the sensitivity of the analysis to regional differences at a small spatial scale (required by small structures, such as the PC), we smoothed the GM volume images using a small isotropic Gaussian kernel with a 6-mm full width at half maximum. This kernel width ensures that any non-normality in the error term is sufficiently attenuated in balanced designs to render the tests valid

\section{Olfactory-related regions of interest}

Statistical analyses were performed on brain areas known to play a role in olfactory and memory processing. As no probabilistic maps have been proposed for the olfactory areas, anatomical volume of interests (VOIs) in the PC, amygdala, hippocampus, insula and thalamus were drawn from the study-specific template realigned to the MNI using MRIcron (www.mccauslandcenter.sc.edu/mricro/mricron/) and human brain atlases . The VOIs were drawn from coronal slices for the PC (from $y=12.5$ anterior to -2.7 posterior to the anterior commissure), amygdala (from $y=0$ to -13.3 ), insula (from $y=-22$ to 36 ), and thalamus (from $y=8$ to 29.2 ), and from sagittal slices for the hippocampus (from $\mathrm{x}=-24$ to -38 on the left, and from $\mathrm{x}=24$ to 38 on the right). Based on previous data, the PC was divided along the y-axis into two areas, specifically, the anterior area (spreading from 12.5 to $4 \mathrm{~mm}$ ) and posterior area (spreading from 4 to $-2.7 \mathrm{~mm}$ ). Orbitofrontal cortex (OFC) VOIs were spheres $10 \mathrm{~mm}$ in diameter located at coordinates previously identified by Gottfried and Zald in the left and right hemispheres (Talairach coordinates: -22 30 -17 and 2433 -12) as being the putative secondary olfactory cortex. These areas defining the human olfactory network were combined to form a binary mask to which we added orbital areas (Brodmann areas (BA) 11, 20 and 34) using the WFU_PickAtlas v2.4 software based on the Talairach Daemon database. This mask was further dilated by $6 \mathrm{~mm}$ (the same width as the smoothing kernel employed for GM volume images) for use as an explicit mask in subsequent VBM statistical analyses. 
Statistical Analysis

\section{Voxel-based morphometry analysis}

As it was reported that the anatomical effects of expertise in musicians increase as a function of years of practice, we hypothesized that the effects of expertise could also be correlated with age in perfumers and not in naïve controls who have never undergone any olfactory training. Given this hypothesis, the effect of age was inhomogeneous among the four groups of subjects and had to be modeled separately for each sub-group. Voxelwise GM volume differences between experts and control subjects were statistically tested using multiple regression analysis, including four regressors of interest (age of older experts, older controls, young experts and young controls). To eliminate possible confounding factors associated with gender or with total GM volume, we applied two regressors of no-interest (gender and total GM volume, the latter being obtained using the 'get-totals.m' matlab function, www.cs.ucl.ac.uk/staff/g.ridgway/vbm/). For statistical analysis of the GM images, we excluded all voxels with GM values below 0.2 (absolute threshold masking) to avoid possible edge effects between different tissue types and to only account for GM voxels with high GM volume content. The GM-volume statistical analysis was constrained within the explicit GM olfactory mask defined above.

We tested whether GM volumes differed globally between experts and controls [(YE $+\mathrm{OE})-$ $(\mathrm{YC}+\mathrm{OC})]$ and also assessed the effect of expertise in the younger and older experts compared to their respective controls (contrasts $[\mathrm{YE}-\mathrm{YC}]$ and [OE-OC], respectively). To identify the areas commonly different between the two sub-groups of experts and their respective controls, we computed the voxels that reached the criterion of significance for both contrasts [YE-YC] and [OEOC]. Finally, to test for differences in brain volumes between the expert sub-groups, we performed contrasts for $[(\mathrm{YE}-\mathrm{YC})-(\mathrm{OE}-\mathrm{OC})]$ and $[(\mathrm{OE}-\mathrm{OC})-(\mathrm{YE}-\mathrm{YC})]$. For all the contrasts, we applied Student's $t$-test with a height of threshold on individual voxels such that $p_{\text {uncorrected }}<0.001$ and a threshold on spatial extent such that the probability on the extent was $p_{k}<0.05$. 


\section{VOI-based analysis}

For each olfactory-related VOI and each of the 48 participants, we derived the adjusted values from the previous general linear model analysis, by removing any contribution from no-interest variables within the VOI. For each VOI, three-way ANOVA (Group x Age x Side) and mean posthoc comparisons were performed using Statistica 6.0 (StatSoft ${ }$, Tulsa, OK, USA) to compare the degree of change in GM volume as a function of the groups (controls and experts), age (younger and older) and brain sides (left and right). We tested the null hypothesis that there were no significant changes of GM in each of the seven VOIs (the aPC, pPC, OFC, amygdala, hippocampus, insula and thalamus). To control for Type I error rate, we applied the Bonferroni correction by dividing the probability $\alpha$ per the number of VOIs (pcorrected $=0.007$ ).

\section{Regression analyses}

On the bilateral aPC and pPC VOIs, and two GR/MOG clusters evidenced on the left side (-9 23 -15 and -8 26 -24) with classical general linear model analysis as being dependent of expertise, we performed linear regression analyses to test for significant relationships between the years of age and volume of GM either in older experts or in older controls using Statistica 6.0 (StatSoft®, Tulsa, OK, USA). In older experts, years from 20 years-old (when their training started) were considered as years of practice and thus reflected the length of expertise. In the controls matched in age, we also removed 20 years to their age in order to compare with the professional experts. The regression lines of the expert and control groups were compared for parallelism and common intercepts to respectively test whether the relationships between expertise and GM volume (slopes of the regression lines) were different, and whether the volume variations began at identical levels of expertise (intersection of the regression lines with the y-axis). As an effect of expertise on the greymatter volume could be predicted for each of these 6 VOIs, we applied the Bonferroni correction ( $p$ $=0.0083)$. 


\section{Results}

Statistical results of the analyses of GM volume in the four groups of subjects are presented in Table 1 . When contrasting the GM volumes between all experts and controls $[(\mathrm{YE}+\mathrm{OE})-(\mathrm{YC}+$ OC)], we observed a bilateral pattern of increased volume spreading from the gyrus rectus (GR) to the medial orbital gyrus (MOG), and an increased GM volume in the anterior cingulate gyrus and the caudate nucleus (Fig. 1A). In YE compared with YC (YE - YC), we observed an increased GM volume in the left and right GR/MOG and in the left anterior cingulate gyrus. In OE compared with OC (OE - OC), a higher GM volume was observed in an anterior area of the left GR/MOG and in the left caudate nucleus. Although reaching the criterion of significance at peak level only, the conjunction analysis between contrasts applied in both sub-groups of experts when compared to their respective controls $[(\mathrm{YE}-\mathrm{YC})$ and $(\mathrm{OE}-\mathrm{OC})]$ revealed a common pattern of increased GM volume in the right gyrus rectus (x y z coordinates, 927 -24). The interactions [(OE - OC) - (YE $\mathrm{YC})]$ and $[(\mathrm{YE}-\mathrm{YC})$ - (OE - OC)] did not reveal any significant differences in GM volume, demonstrating no significant influence of sub-groups on the effect of expertise. No significant decrease in GM volume was observed in experts when compared with controls regardless of the comparisons.

Anatomical VOI analyses did not reveal any significant group effect in the VOIs ( $\left.p_{\text {corrected }}\right)$, although a group effect was noted in the posterior PC with a $p_{\text {uncorrected }}(F(1,44)=4.00, p=0.044)$, suggesting a volume of GM tending to be higher in experts than in control participants. Significant Group x Side interactions were observed for the amygdala $(F(1,44)=13.01, p=0.001)$, insula $(F(1,44)=56.99, p<0.001)$ and thalamus $(F(1,44)=16.45, p<0.001)$; however, post-hoc comparisons did not show any significant difference between groups for a given side $(p ’ s>0.007)$, but only significant differences between both sides in experts and/or controls.

We subsequently examined whether the GM volume in older experts depended on the duration of practice (and therefore on the level of expertise). In the left gyrus rectus (Lower part: -9 23 -15; 
Upper part: -8 $26-24$; Fig. 2A), the volume of the GM was significantly positively correlated with the age (and therefore the level of expertise) in OE (Upper part: $r=0.685, F(1,12)=10.62, p=$ 0.007; Lower part: $r=0.677, F(1,12)=10.13, p=0.008)$, while it tended to be significantly negatively correlated with age in EC in the upper part $(r=-0.649, F(1,11)=8.00, p=0.016)$ and it was not significant in the lower part $(r=-0.50, F(1,11)=3.58, p=0.085)$. Regression lines obtained in OE and OC were significantly not parallel in both areas (Upper part: $T(27)=4.21, p<$ 0.001 ; Lower part: $T(27)=3.42, p=0.002)$, and they had common intercepts $(T(27)=1.90, p=$ 0.068 and $T(27)=1.52, p=0.139$, respectively).

The GM volume of the anterior PC (Fig. 3B) was not significantly positively correlated with expertise level in OE in the left $(r=0.486, F(1,12)=3.71, p=0.078)$ and the right $(r=0.401$, $F(1,12)=2.30, p=0.155)$ sides, but tended to be significantly negatively correlated ( $\left.p_{\text {uncorrected }}\right)$ in OC in both sides (Left: $r=-0.582, F(1,11)=5.64, p=0.037$; Right: $r=-0.623, F(1,11)=6.69, p=$ 0.023). Regression lines for OE and OC data were significantly not parallel (Left: $T_{27}=3.03, p=$ 0.005; Right: $T(27)=2.84, p=0.009)$ and had common intercepts for the right anterior PC $(T(27)$ $=-1.74, p=0.093)$. 


\section{Discussion}

By combining the structural imaging and VBM technique with the best and most recent improvements, we showed structural modifications related to olfactory expertise. Compared with naïve subjects, the student and professional perfumers mainly presented a bilateral GM increase in the GR/MOG, an area that marks the borders of the olfactory sulcus and that is adjacent to the putative secondary olfactory cortex. Furthermore, when considering the professional experts only, expertise seems to counteract the effect of age in the GR/MOG and anterior PC, as the GM volumes increased with years of practice, whereas they decreased with age in naïve subjects.

\section{Structural and functional characteristics of the GR/MOG}

All olfactory experts showed an increased GM volume in the GR/MOG compared with control subjects who had no expertise in olfaction. Volume increase was bilateral in the GR/MOG more posterior part and was left-sided in the more anterior part.

Very few studies have shown an increase of GM volume in olfactory areas in relation with olfactory abilities in normosmic volunteers. They demonstrated that the size of the olfactory bulb and/or the depth of the left olfactory sulcus significantly correlated with olfactory performances in healthy subjects and in individuals who became blind early in life . If the olfactory bulb is mostly considered to be a peripheral structure, the depth of the olfactory sulcus can reflect the size of the adjacent cerebral cortex. Using an automated method for extracting the cortical thickness, Frasnelli et al. found an increase in cortical thickness with higher olfactory abilities in an area surrounding the left olfactory sulcus in healthy volunteers. This region is very close to the GR/MOG evidenced in our study, and allows dismissing the interpretation of the current results as resulting from methodological artifact. Recently, applying classical volumetry and VBM methodologies in healthy subjects, Seubert et al. dissociated the functional contributions of olfactory peripheral and central areas. They found that the volume of the olfactory bulb increased with higher identification scores, while the volume of GM in the OFC was enhanced with better olfactory threshold and 
discrimination performances. Because the authors limited their investigation to a unique area of the OFC that approximately covered the putative human olfactory OFC evidenced by Gottfried and Zald but did not include the GR/MOG regions, the comparison with our data is impossible.

However, it is surprising that we did not observe any change of GM volume in this region in the odor experts.

What is the role of the GR/MOG region? In monkeys, the GR/MOG is referred as being area $11 \mathrm{~m}$ and is a zone located at the level of the olfactory sulcus delimited by the dysgranular areas $13 \mathrm{~m}, 13 \mathrm{~b}$ and $14 \mathrm{r}$. Studying architectonic maps and the intrinsic cortico-cortical connections within the orbital and the medial prefrontal cortex, Carmichael and Price distinguished two distinct networks, the "orbital network" (including in particular areas $13 \mathrm{~b}$ and $13 \mathrm{~m}$ ) that receives inputs related to most of the sensory modalities and the "medial network" (including in particular areas $11 \mathrm{~m}$ and $14 \mathrm{r}$ ) that receives a few direct olfactory inputs, but does not receive inputs from other sensory modalities. Because all of the areas recognized in the macaque medial prefrontal cortex have their counterparts in humans, the question is to know what is the role of the GR/MOG in humans. In an attempt to explain the respective role of these two networks, the authors suggested that the orbital network appears to be related to feeding and reward, whereas the medial network seems to participate in the guidance of emotional behavior . Rather than a coarse medial/lateral distinction, Kahnt et al. recently identified 6 subdivisions in the human OFC from their functional connectivity profiles with other brain regions. They suggested a role of the medial and centralposterior regions in reward processing and reward learning, respectively.

In cerebral imaging studies on human olfactory processes, the GR/MOG was found to be activated in several studies, although often described with different labels (such as the rostromedial or posterior OFC, ventromedial prefrontal cortex, inferior frontal gyrus, cingulate gyrus, or subcallosum), depending on the atlases and nomenclatures. Interestingly, this brain region is different from the putative olfactory OFC evidenced by Gottfried and Zald . The GR/MOG could therefore be associated to more higher-order cognitive process in comparison to this putative 
olfactory OFC which was identified from data for which no cognitive olfactory judgment and no aversive odorants were used. A functional segregation of valence neural representations has been observed in the OFC, the medial part being more strongly activated by pleasant odors, and the lateral part being more notably activated by unpleasant odors, a representation that holds even when the attributed hedonic properties are modulated by cognitive information . Similar findings were observed with taste and flavor, the processing of faces, and monetary reward and punishment . Since the perfumers intensively and daily use pleasant odorants in order to make fragrances, as suggested by testimonies, the question is whether this hyper-use can explain structural changes observed in the GR/MOG. Further investigations are needed to clarify this point.

We further observed additional GM changes in the anterior cingulate gyrus in student perfumers and in the caudate nucleus in professional perfumers, which are two areas that are commonly activated in olfaction. Structural modifications in these regions are in accordance with the cognitive functions that are widely used in experts of all types including perfumers. The anterior cingulate gyrus is predicted to play an important role in tasks requiring cognitive control in the presence of emotional stimuli while the caudate nucleus is highly involved in learning and memory .

\section{Dynamic changes of GM volume in olfactory areas}

Here, we observed that intensive olfactory training counteracts the effect of age in several brain regions. Thus, although the increases were not systematically significantly positively correlated with experience in these areas in older perfumers, they were strengthened by the fact that the GM volume was reduced with age in controls and that the respective slopes of both regression lines were then systematically significantly different. Thus, the older an individual gets, the more the anterior PC and GR/MOG volumes relatively increase in experts and the more they decrease in untrained subjects. Volume reduction in controls is consistent with the well-known decline of global GM volume with age . Hedman et al. have shown that after 35 years-old, a steady volume loss of $0.2 \%$ per year is found, which accelerates gradually to an annual brain volume loss of $0.5 \%$ at age 60 .

Overall, these double morphometry data demonstrate a causal direction between olfactory 
abilities and GM volume of olfactory areas. When the two lines of regression present a common intercept but different slopes, this means that experts and controls had the same GM volume at the same age (approximately 20 years old), but that this volume changes differently with respect to age by increasing in odor experts and decreasing in controls. These data also allow claiming that longer olfactory training leads to larger GM volumes, a finding that must be related to our previous results observed in the same subjects and showing behavioral performances enhanced with expertise . Structural changes in odor experts are further consistent with cross-sectional VBM studies that demonstrate learning-dependent changes in the adult human brain and suggest anatomical correlates for navigation, arithmetic, linguistic, procedural, and musical learning abilities . Structural changes have even been observed after brief periods of learning, such as after studying for three months after an exam or even after a very short spatial learning of 2 hours .

\section{Neuronal mechanisms related to olfactory learning}

Perceptual learning refers to a phenomenon whereby experience refines sensory perception through the differentiation of stimulus features, dimensions, or categories of items that was previously experienced. It has previously been showed that experience and familiarity enhance odor quality discrimination. Training to taste wine and beer also improves the ability to discriminate flavors . Recently, Li et al. showed that prolonged exposure $(3.5 \mathrm{~min})$ to a floral-smelling odorant enhances perceptual differentiation only for novel odorants that are related in odor quality or functional group, indicating that subjects become floral "experts." This effect was paralleled by increased responses in the posterior PC and interestingly an area close to the medial OFC (-14 30 -14), as observed here. The authors speculated that this learning-induced plasticity could reflect two neuronal mechanisms, an enlargement in cortical receptive fields, which results in the recruitment of more neurons (spatial summation), or alternatively a synchronization of neuronal activity (temporal summation) .

The current experiment is the first to investigate the structural impact of odor long-term training. Perfumers live in an enriched olfactory environment and learn to characterize and recognize 
numerous stimuli daily, and to discriminate often minute differences between them. This paper follows its functional counterpart in which we demonstrate a signal decrease in hyper-trained perfumers in olfactory (piriform cortex and OFC) and memory (hippocampus) brain regions when they generate a mental image of odor. A signal decrease could be because of a greater selectivity of neurons due to a decorrelation of their activity. Similar mechanisms have been shown in the antennal lobe of the honeybees trained on one odorant, the sensorial representation of that odorant becoming smaller, more compact, and nonoverlapping with other odorants and in rats trained to discriminate highly overlapping odorous mixtures . As an attempt to conciliate the structural and functional reorganizations of olfactory experts, we speculate that although cells become more selective after perceptual learning, perfumers could present an enlargement of the cortical surface dedicated to odor representation, and correlatively present a GM volume increase.

\section{Cellular events underlying structural changes}

The nature of the cellular events that underlie structural changes in the human brain is still unknown, although it is widely assumed that GM loss in neurodegeneration corresponds to neural loss . First, GM increase can be due to fast morphological changes such as the formation of new connections by dendritic spine growth . Thus, a three-day olfactory learning in rats is accompanied by a dendritic spine density increase (15\%) along apical dendrites of PC pyramidal neurons, suggesting an increased number of excitatory synapses. Second, GM increase can be related to slow mechanisms, such as adult neurogenesis that has been reported in the olfactory bulb and the PC . In the olfactory bulb, it was associated with an improvement in short-term olfactory memory when mice were exposed daily to a novel enriched olfactory environment . Here, we suggest that a GM volume increase in the anterior PC could mainly result both from a fast remodeling of the intracortical neuronal network, but genesis of new neurons in this brain area cannot be excluded. 
The current study showed that olfactory expertise is concomitant with a structural reorganization in primary areas and the OFC. We revealed a GM volume increase in the bilateral GR/MOG and a trend for a GM increase in the posterior PC in odor experts compared with naïve subjects. More strikingly, the GM volume in the left GR/MOG and bilateral anterior PC was positively correlated with experience. These findings are consistent with our previous data showing that perfumers present an expertise-dependent functional reorganization in olfactory and memory areas. In summary, together with our previous experiment, long-term olfactory training leads to the acquisition of highly specific knowledge, which enables the generation of odor mental images and is paralleled by the structural and functional reorganization of olfactory areas. 


\section{Legends}

Fig. 1. Whole-brain structural modifications as a function of expertise. Increased GM volumes were observed in (A) the gyrus rectus in all experts (Exp) when compared with all controls (Cont), (B) the cingulate gyrus in young experts (YE) when compared with young controls (YC), and (C) the gyrus rectus and caudate nucleus in older experts (OE) when compared with older controls (OC). Graphs: data adjusted for gender and total GM volume in experts and controls. Vertical bars, standard error of the mean. GM: gray matter.

Fig. 2. Relationship between structural modifications and years of age. Positive slope in older experts (OE, green) and negative slope in older controls (OC, blue) of regression lines between the GM volume and years of age (from 20 to 60 years old) in A) the left GR/MOG and B) left and right anterior piriform cortex. GR/MOG, gyrus rectus/medial orbital gyrus.

Table 1. Whole-brain structural modifications as a function of expertise in 1) all experts $v s$. all controls; 2) Younger experts vs. their controls; 3) Older experts vs. their controls. 
Table 1

\begin{tabular}{|c|c|c|c|c|c|c|c|c|}
\hline \multirow[t]{2}{*}{ Contrast } & \multirow[t]{2}{*}{ Region } & \multirow[t]{2}{*}{ BA } & \multirow[t]{2}{*}{ Side } & \multicolumn{2}{|c|}{ Statistics } & \multicolumn{3}{|c|}{ Coordinates } \\
\hline & & & & $k$ & $T$ & $x$ & $y$ & $z$ \\
\hline \multirow[t]{5}{*}{ Exp - Cont } & GR/MOG & $11 \mathrm{~m}$ & $\mathrm{~L}$ & 2021 & 6.83 & -8 & 41 & -24 \\
\hline & GR/MOG & $14 r / 13 b$ & $\mathrm{R}$ & & 6.00 & 9 & 27 & -23 \\
\hline & MOG & $13 \mathrm{~b} / 13 \mathrm{~m}$ & $\mathrm{~L}$ & & 4.90 & -15 & 35 & -23 \\
\hline & Anterior cingulate gyrus & $32 \mathrm{ac}$ & $\mathrm{L}$ & 355 & 5.13 & -3 & 39 & 16 \\
\hline & Caudate nucleus & & $\mathrm{L}$ & 552 & 4.91 & -14 & 6 & 21 \\
\hline \multirow[t]{5}{*}{$\mathrm{YE}-\mathrm{YC}$} & GR/MOG & $11 \mathrm{~m}$ & $\mathrm{~L}$ & 296 & 6.65 & -9 & 42 & -26 \\
\hline & MOG & $13 \mathrm{~m}$ & $\mathrm{~L}$ & & 4.57 & -15 & 35 & -23 \\
\hline & GR/MOG & $14 r / 13 b$ & $\mathrm{R}$ & 516 & 4.87 & 9 & 27 & -20 \\
\hline & GR/MOG & $11 \mathrm{~m}$ & $\mathrm{R}$ & & 4.07 & 9 & 36 & -20 \\
\hline & Anterior cingulate gyrus & $32 \mathrm{ac}$ & $\mathrm{L}$ & 264 & 4.27 & -3 & 39 & 16 \\
\hline \multirow[t]{4}{*}{$\mathrm{OE}-\mathrm{OC}$} & Caudate nucleus & & $\mathrm{L}$ & 503 & 5.57 & -14 & 14 & 16 \\
\hline & & & $\mathrm{L}$ & & 5.47 & -15 & 6 & 21 \\
\hline & GR/MOG & $14 r / 13 b$ & $\mathrm{~L}$ & 395 & 4.12 & -8 & 26 & -24 \\
\hline & & $14 \mathrm{r}$ & $\mathrm{L}$ & & & -9 & 23 & -15 \\
\hline
\end{tabular}

Abbreviations: Exp, All experts; Cont, All controls; OE, older expert; OC, older control; YE, young expert; YC, young control; GR/MOG, Gyrus rectus/Medial orbital gyrus; BA, Brodmann area L, left; R, right. 

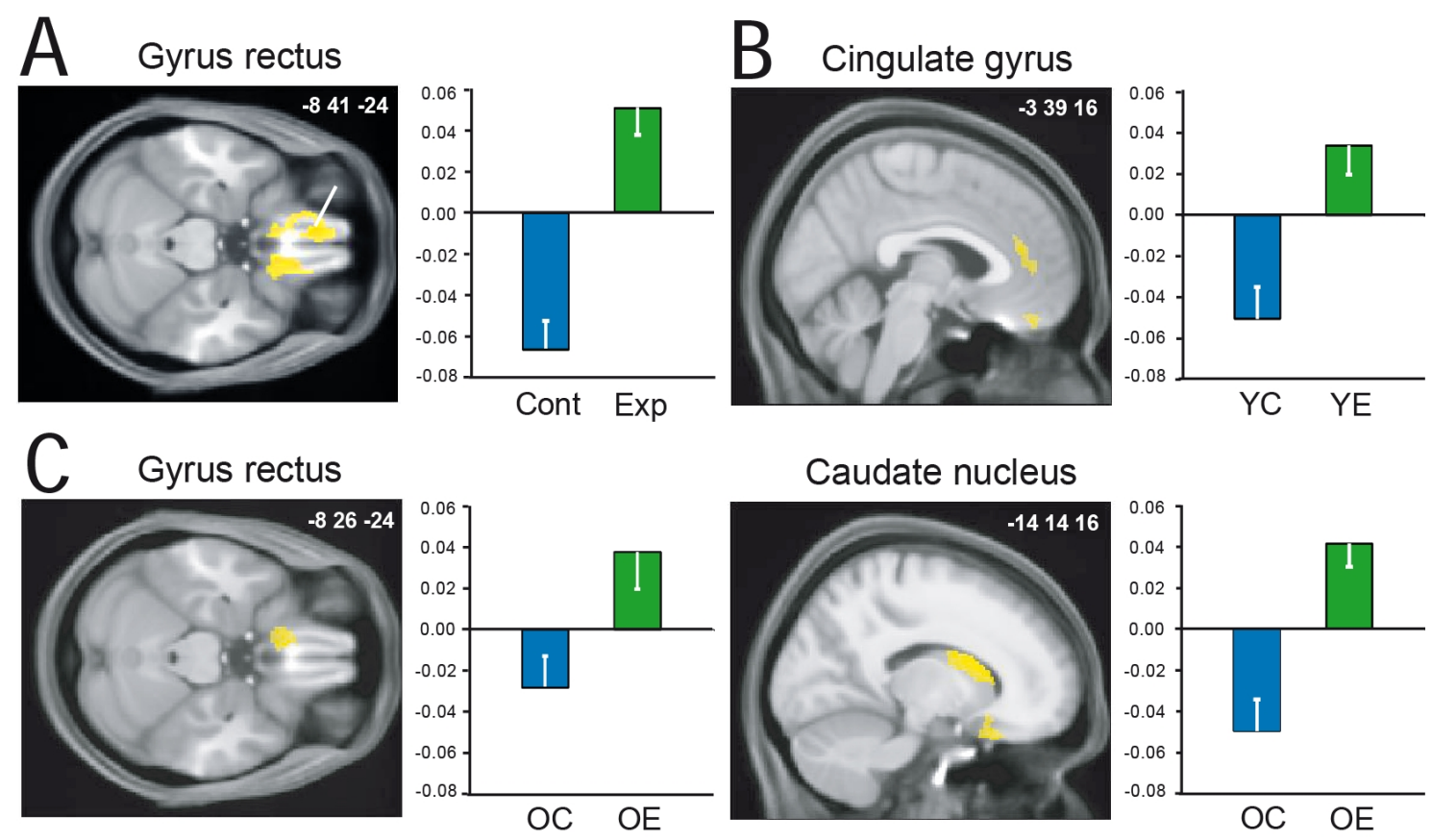

Caudate nucleus
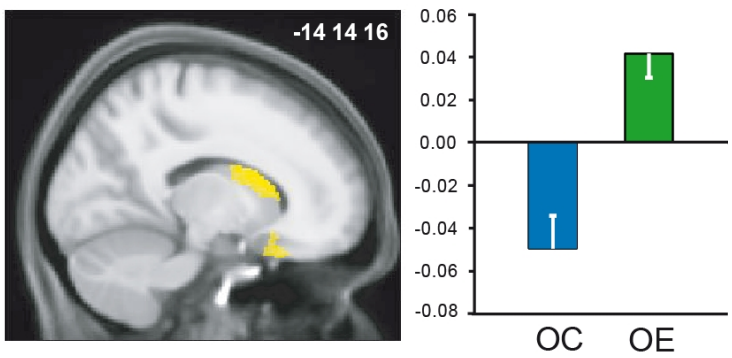

Figure 1 to be reproduced in color on the Web only 

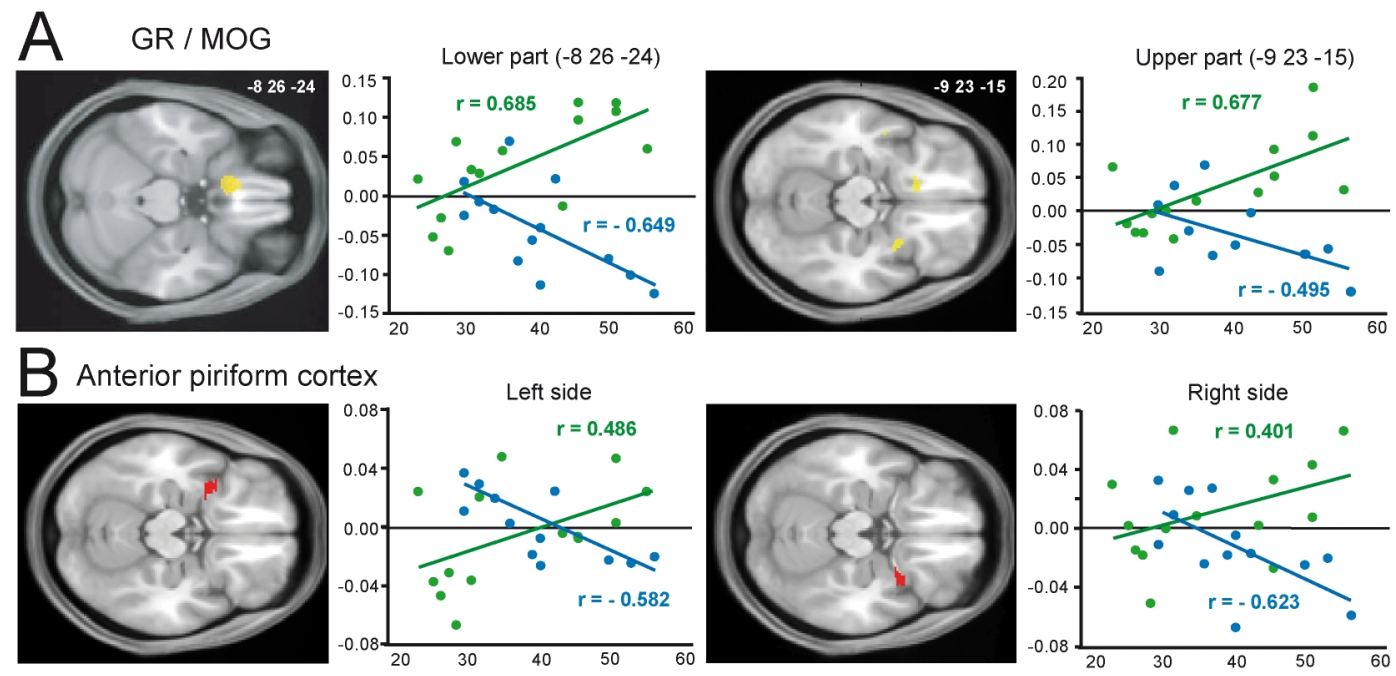

Figure 2 to be reproduced in color on the Web only 


\section{Acknowledgments}

This work was supported by the Roudnitska Foundation, the Centre National de la Recherche Scientifique (CNRS), and the Institut National de la Santé et de la Recherche Médicale (INSERM).

We thank the editors of American Journal Experts for careful checking of English of the manuscript. 


\section{References}

Abolmaali, N.D., Hietschold, V., Vogl, T.J., Huttenbrink, K.B., Hummel, T., 2002. MR evaluation in patients with isolated anosmia since birth or early childhood. AJNR Am J Neuroradiol 23, 157-164.

Acosta-Cabronero, J., Williams, G.B., Pereira, J.M., Pengas, G., Nestor, P.J., 2008. The impact of skull-stripping and radio-frequency bias correction on grey-matter segmentation for voxel-based morphometry. Neuroimage 39, 1654-1665.

Anderson, A.K., Christoff, K., Stappen, I., Panitz, D., Ghahremani, D.G., Glover, G., Gabrieli, J.D., Sobel, N., 2003. Dissociated neural representations of intensity and valence in human olfaction. Nat Neurosci 6, 196-202.

Ashburner, J., 2007. A fast diffeomorphic image registration algorithm. Neuroimage 38, 95-113. Ashburner, J., Friston, K.J., 2000. Voxel-based morphometry--the methods. Neuroimage 11, 805821.

Ashburner, J., Friston, K.J., 2005. Unified segmentation. Neuroimage 26, 839-851.

Baron, J.C., Chetelat, G., Desgranges, B., Perchey, G., Landeau, B., de la Sayette, V., Eustache, F., 2001. In vivo mapping of gray matter loss with voxel-based morphometry in mild Alzheimer's disease. Neuroimage 14, 298-309.

Bengtsson, S.L., Nagy, Z., Skare, S., Forsman, L., Forssberg, H., Ullen, F., 2005. Extensive piano practicing has regionally specific effects on white matter development. Nat. Neurosci. 8, 1148-1150.

Berglund, H., Lindstrom, P., Dhejne-Helmy, C., Savic, I., 2008. Male-to-female transsexuals show sex-atypical hypothalamus activation when smelling odorous steroids. Cereb Cortex 18, 1900-1908.

Bermudez, P., Zatorre, R.J., 2005. Differences in gray matter between musicians and nonmusicians. Ann N Y Acad Sci 1060, 395-399.

Bernier, P.J., Bedard, A., Vinet, J., Levesque, M., Parent, A., 2002. Newly generated neurons in the amygdala and adjoining cortex of adult primates. Proc Natl Acad Sci U S A 99, 11464-11469.

Bitter, T., Bruderle, J., Gudziol, H., Burmeister, H.P., Gaser, C., Guntinas-Lichius, O., 2010a. Gray and white matter reduction in hyposmic subjects--A voxel-based morphometry study. Brain Res $1347,42-47$.

Bitter, T., Gudziol, H., Burmeister, H.P., Mentzel, H.J., Guntinas-Lichius, O., Gaser, C., 2010 b. Anosmia leads to a loss of gray matter in cortical brain areas. Chem Senses 35, 407-415.

Bookstein, F.L., 2001. "Voxel-based morphometry" should not be used with imperfectly registered images. Neuroimage 14, 1454-1462.

Boyle, J.A., Frasnelli, J., Gerber, J., Heinke, M., Hummel, T., 2007. Cross-modal integration of intranasal stimuli: a functional magnetic resonance imaging study. Neuroscience 149, 223-231.

Buschhuter, D., Smitka, M., Puschmann, S., Gerber, J.C., Witt, M., Abolmaali, N.D., Hummel, T., 2008. Correlation between olfactory bulb volume and olfactory function. Neuroimage 42, 498-502.

Carmichael, S.T., Clugnet, M.C., Price, J.L., 1994. Central olfactory connections in the macaque monkey. J Comp Neurol 346, 403-434.

Carmichael, S.T., Price, J.L., 1994. Architectonic subdivision of the orbital and medial prefrontal cortex in the macaque monkey. J Comp Neurol 346, 366-402.

Carmichael, S.T., Price, J.L., 1995. Limbic connections of the orbital and medial prefrontal cortex in macaque monkeys. J Comp Neurol 363, 615-641.

Carmichael, S.T., Price, J.L., 1996. Connectional networks within the orbital and medial prefrontal cortex of macaque monkeys. J Comp Neurol 371, 179-207.

Chapuis, J., Wilson, D.A., 2012. Bidirectional plasticity of cortical pattern recognition and 
behavioral sensory acuity. Nat. Neurosci. 15, 155-161.

Ciumas, C., Linden Hirschberg, A., Savic, I., 2009. High fetal testosterone and sexually dimorphic cerebral networks in females. Cereb Cortex 19, 1167-1174.

Collet, S., Grulois, V., Bertrand, B., Rombaux, P., 2009. Post-traumatic olfactory dysfunction: a cohort study and update. B-Ent 5 Suppl 13, 97-107.

Cross, E.S., Hamilton, A.F., Grafton, S.T., 2006. Building a motor simulation de novo: observation of dance by dancers. Neuroimage 31, 1257-1267.

Curtis, M.A., Kam, M., Faull, R.L., 2011. Neurogenesis in humans. Eur J Neurosci 33, 1170-1174. de Araujo, I.E., Rolls, E.T., Velazco, M.I., Margot, C., Cayeux, I., 2005. Cognitive modulation of olfactory processing. Neuron 46, 671-679.

Draganski, B., Gaser, C., Busch, V., Schuierer, G., Bogdahn, U., May, A., 2004. Neuroplasticity: changes in grey matter induced by training. Nature 427, 311-312.

Draganski, B., Gaser, C., Kempermann, G., Kuhn, H.G., Winkler, J., Buchel, C., May, A., 2006. Temporal and spatial dynamics of brain structure changes during extensive learning. J Neurosci 26, 6314-6317.

Duvernoy, H.M., 1999. The Human Brain Surface, Three Dimentional Sectional Anatomy and MRI, 2nd ed. SpringerWien, New York.

Faber, T., Joerges, J., Menzel, R., 1999. Associative learning modifies neural representations of odors in the insect brain. Nat Neurosci 2, 74-78.

Focke, N.K., Helms, G., Kaspar, S., Diederich, C., Toth, V., Dechent, P., Mohr, A., Paulus, W., 2011. Multi-site voxel-based morphometry--not quite there yet. Neuroimage 56, 1164-1170.

Frasnelli, J., Lundstrom, J.N., Boyle, J.A., Djordjevic, J., Zatorre, R.J., Jones-Gotman, M., 2010. Neuroanatomical correlates of olfactory performance. Exp Brain Res 201, 1-11.

Garcia-Falgueras, A., Junque, C., Gimenez, M., Caldu, X., Segovia, S., Guillamon, A., 2006. Sex differences in the human olfactory system. Brain Res 1116, 103-111.

Gaser, C., Schlaug, G., 2003a. Brain structures differ between musicians and non-musicians. J Neurosci 23, 9240-9245.

Gaser, C., Schlaug, G., 2003b. Gray matter differences between musicians and nonmusicians. Ann N Y Acad Sci 999, 514-517.

Gilbert, C.D., Sigman, M., Crist, R.E., 2001. The neural basis of perceptual learning. Neuron 31, 681-697.

Golestani, N., Paus, T., Zatorre, R.J., 2002. Anatomical correlates of learning novel speech sounds. Neuron 35, 997-1010.

Gonzalez, J., Barros-Loscertales, A., Pulvermuller, F., Meseguer, V., Sanjuan, A., Belloch, V., Avila, C., 2006. Reading cinnamon activates olfactory brain regions. Neuroimage 32, 906-912.

Good, C.D., Johnsrude, I.S., Ashburner, J., Henson, R.N., Friston, K.J., Frackowiak, R.S., 2001. A voxel-based morphometric study of ageing in 465 normal adult human brains. Neuroimage 14, 21 36.

Gottfried, J.A., Deichmann, R., Winston, J.S., Dolan, R.J., 2002. Functional heterogeneity in human olfactory cortex: an event-related functional magnetic resonance imaging study. J Neurosci 22, 10819-10828.

Gottfried, J.A., Zald, D.H., 2005. On the scent of human olfactory orbitofrontal cortex: metaanalysis and comparison to non-human primates. Brain Res Rev 50, 287-304.

Grabenhorst, F., Rolls, E.T., Margot, C., da Silva, M.A., Velazco, M.I., 2007. How pleasant and unpleasant stimuli combine in different brain regions: odor mixtures. J Neurosci 27, 13532-13540.

Graybiel, A.M., 2005. The basal ganglia: learning new tricks and loving it. Curr Opin Neurobiol 15, 638-644. 
Gulyas, B., Keri, S., O'Sullivan, B.T., Decety, J., Roland, P.E., 2004. The putative pheromone androstadienone activates cortical fields in the human brain related to social cognition. Neurochem Int 44, 595-600.

Haehner, A., Rodewald, A., Gerber, J.C., Hummel, T., 2008. Correlation of olfactory function with changes in the volume of the human olfactory bulb. Arch Otolaryngol Head Neck Surg 134, 621624.

Hedman, A.M., van Haren, N.E., Schnack, H.G., Kahn, R.S., Hulshoff Pol, H.E., 2011. Human brain changes across the life span: A review of 56 longitudinal magnetic resonance imaging studies. Hum Brain Mapp.

Hummel, T., Damm, M., Vent, J., Schmidt, M., Theissen, P., Larsson, M., Klussmann, J.P., 2003. Depth of olfactory sulcus and olfactory function. Brain Res 975, 85-89.

Hummel, T., Iannilli, E., Frasnelli, J., Boyle, J., Gerber, J., 2009. Central processing of trigeminal activation in humans. Ann N Y Acad Sci 1170, 190-195.

Ibarretxe-Bilbao, N., Junque, C., Marti, M.J., Valldeoriola, F., Vendrell, P., Bargallo, N., Zarei, M., Tolosa, E., 2010. Olfactory impairment in Parkinson's disease and white matter abnormalities in central olfactory areas: A voxel-based diffusion tensor imaging study. Mov Disord 25, 1888-1894.

Jacobson, A., Green, E., Murphy, C., 2010. Age-related functional changes in gustatory and reward processing regions: An fMRI study. Neuroimage 53, 602-610.

Jancke, L., 2009. The plastic human brain. Restor Neurol Neurosci 27, 521-538.

Jehl, C., Royet, J.P., Holley, A., 1995. Odor discrimination and recognition memory as a function of familiarization. Percept Psychophys 57, 1002-1011.

Kahnt, T., Chang, L.J., Park, S.Q., Heinzle, J., Haynes, J.D., 2012. Connectivity-based parcellation of the human orbitofrontal cortex. J Neurosci 32, 6240-6250.

Kareken, D.A., Mosnik, D.M., Doty, R.L., Dzemidzic, M., Hutchins, G.D., 2003. Functional anatomy of human odor sensation, discrimination, and identification in health and aging. Neuropsychology 17, 482-495.

Kleber, B., Veit, R., Birbaumer, N., Gruzelier, J., Lotze, M., 2010. The Brain of Opera Singers: Experience-Dependent Changes in Functional Activation. Cereb Cortex 20, 1144-1152.

Klein, A., Ghosh, S.S., Avants, B., Yeo, B.T., Fischl, B., Ardekani, B., Gee, J.C., Mann, J.J., Parsey, R.V., 2010. Evaluation of volume-based and surface-based brain image registration methods.

Neuroimage 51, 214-220.

Kleinbaum, D.G., Kupper, L.L., Muller, K.E., 1988. Applied Regression Analysis and Other Multivariable Methods, Second ed. PWS-KENT Publishing Company, Boston.

Knafo, S., Grossman, Y., Barkai, E., Benshalom, G., 2001. Olfactory learning is associated with increased spine density along apical dendrites of pyramidal neurons in the rat piriform cortex. Eur J Neurosci 13, 633-638.

Kondo, H., Saleem, K.S., Price, J.L., 2005. Differential connections of the perirhinal and parahippocampal cortex with the orbital and medial prefrontal networks in macaque monkeys. $J$ Comp Neurol 493, 479-509.

Larsson, M., Farde, L., Hummel, T., Witt, M., Lindroth, N.E., Backman, L., 2009. Age-related loss of olfactory sensitivity: association to dopamine transporter binding in putamen. Neuroscience 161, $422-426$.

Li, W., Luxenberg, E., Parrish, T., Gottfried, J.A., 2006. Learning to smell the roses: experiencedependent neural plasticity in human piriform and orbitofrontal cortices. Neuron 52, 1097-1108.

Lotze, M., Halsband, U., 2006. Motor imagery. J Physiol Paris 99, 386-395.

Luders, E., Gaser, C., Jancke, L., Schlaug, G., 2004. A voxel-based approach to gray matter asymmetries. Neuroimage 22, 656-664.

Maguire, E.A., Gadian, D.G., Johnsrude, I.S., Good, C.D., Ashburner, J., Frackowiak, R.S., Frith, 
C.D., 2000. Navigation-related structural change in the hippocampi of taxi drivers. Proc Natl Acad Sci USA 97, 4398-4403.

Mai, J.K., Paxinos, G., Voss, T., 2008. Atlas of the human brain, Third ed. Academic Press, San Diego (CA).

Maldjian, J.A., Laurienti, P.J., Kraft, R.A., Burdette, J.H., 2003. An automated method for neuroanatomic and cytoarchitectonic atlas-based interrogation of fMRI data sets. Neuroimage 19, 1233-1239.

May, A., 2011. Experience-dependent structural plasticity in the adult human brain. Trends Cogn Sci 15, 475-482.

Mechelli, A., Crinion, J.T., Noppeney, U., O'Doherty, J., Ashburner, J., Frackowiak, R.S., Price, C.J., 2004. Neurolinguistics: structural plasticity in the bilingual brain. Nature 431, 757.

Mietchen, D., Gaser, C., 2009. Computational morphometry for detecting changes in brain structure due to development, aging, learning, disease and evolution. Front Neuroinformatics 3, 25.

Ming, G.L., Song, H., 2011. Adult neurogenesis in the mammalian brain: significant answers and significant questions. Neuron 70, 687-702.

Mohanty, A., Engels, A.S., Herrington, J.D., Heller, W., Ho, M.H., Banich, M.T., Webb, A.G., Warren, S.L., Miller, G.A., 2007. Differential engagement of anterior cingulate cortex subdivisions for cognitive and emotional function. Psychophysiology 44, 343-351.

Mueller, A., Rodewald, A., Reden, J., Gerber, J., von Kummer, R., Hummel, T., 2005. Reduced olfactory bulb volume in post-traumatic and post-infectious olfactory dysfunction. Neuroreport 16 , 475-478.

O'Doherty, J., Kringelbach, M.L., Rolls, E.T., Hornak, J., Andrews, C., 2001. Abstract reward and punishment representations in the human orbitofrontal cortex. Nat Neurosci 4, 95-102.

O'Doherty, J., Winston, J., Critchley, H., Perrett, D., Burt, D.M., Dolan, R.J., 2003. Beauty in a smile: the role of medial orbitofrontal cortex in facial attractiveness. Neuropsychologia 41, 147155.

Ongur, D., Ferry, A.T., Price, J.L., 2003. Architectonic subdivision of the human orbital and medial prefrontal cortex. J Comp Neurol 460, 425-449.

Ongur, D., Price, J.L., 2000. The organization of networks within the orbital and medial prefrontal cortex of rats, monkeys and humans. Cereb Cortex 10, 206-219.

Osterbauer, R.A., Wilson, J.L., Calvert, G.A., Jezzard, P., 2006. Physical and physiological consequences of passive intra-oral shimming. Neuroimage 29, 245-253.

Owen, D.H., Machamer, P.K., 1979. Bias-free improvement in wine discrimination. Perception 8 , 199-209.

Pell, G.S., Briellmann, R.S., Chan, C.H., Pardoe, H., Abbott, D.F., Jackson, G.D., 2008. Selection of the control group for VBM analysis: influence of covariates, matching and sample size.

Neuroimage 41, 1324-1335.

Peron, R.M., Allen, G.L., 1988. Attempts to train novices for beer flavor discrimination: a matter of taste. J Gen Psychol 115, 403-418.

Plailly, J., d'Amato, T., Saoud, M., Royet, J.P., 2006. Left temporo-limbic and orbital dysfunction in schizophrenia during odor familiarity and hedonicity judgments. Neuroimage 29, 302-313.

Plailly, J., Delon-Martin, C., Royet, J.P., 2012. Experience induces functional reorganization in brain regions involved in odor imagery in perfumers. Hum Brain Mapp 33, 224-234.

Poellinger, A., Thomas, R., Lio, P., Lee, A., Makris, N., Rosen, B.R., Kwong, K.K., 2001. Activation and habituation in olfaction--an fMRI study. Neuroimage 13, 547-560.

Price, J.L., 2007. Definition of the orbital cortex in relation to specific connections with limbic and visceral structures and other cortical regions. Ann N Y Acad Sci 1121, 54-71.

Rolls, E.T., Kringelbach, M.L., de Araujo, I.E., 2003. Different representations of pleasant and 
unpleasant odours in the human brain. Eur J Neurosci 18, 695-703.

Rombaux, P., Grandin, C., Duprez, T., 2009a. How to measure olfactory bulb volume and olfactory sulcus depth? B-Ent 5 Suppl 13, 53-60.

Rombaux, P., Huart, C., De Volder, A.G., Cuevas, I., Renier, L., Duprez, T., Grandin, C., 2010. Increased olfactory bulb volume and olfactory function in early blind subjects. Neuroreport 21, 1069-1073.

Rombaux, P., Martinage, S., Huart, C., Collet, S., 2009b. Post-infectious olfactory loss: a cohort study and update. B-Ent 5 Suppl 13, 89-95.

Rombaux, P., Weitz, H., Mouraux, A., Nicolas, G., Bertrand, B., Duprez, T., Hummel, T., 2006. Olfactory function assessed with orthonasal and retronasal testing, olfactory bulb volume, and chemosensory event-related potentials. Arch Otolaryngol Head Neck Surg 132, 1346-1351.

Ross, J.S., Tkach, J., Ruggieri, P.M., Lieber, M., Lapresto, E., 2003. The mind's eye: functional MR imaging evaluation of golf motor imagery. AJNR Am J Neuroradiol 24, 1036-1044.

Rupp, C.I., Fleischhacker, W.W., Kemmler, G., Oberbauer, H., Scholtz, A.W., Wanko, C., Hinterhuber, H., 2005. Various bilateral olfactory deficits in male patients with schizophrenia. Schizophr Bull 31, 155-165.

Sabri, M., Kareken, D.A., Dzemidzic, M., Lowe, M.J., Melara, R.D., 2004. Neural correlates of auditory sensory memory and automatic change detection. Neuroimage 21, 69-74.

Sagi, Y., Tavor, I., Hofstetter, S., Tzur-Moryosef, S., Blumenfeld-Katzir, T., Assaf, Y., 2012. Learning in the fast lane: new insights into neuroplasticity. Neuron 73, 1195-1203.

Saleem, K.S., Kondo, H., Price, J.L., 2008. Complementary circuits connecting the orbital and medial prefrontal networks with the temporal, insular, and opercular cortex in the macaque monkey. J Comp Neurol 506, 659-693.

Salmond, C.H., Ashburner, J., Vargha-Khadem, F., Connelly, A., Gadian, D.G., Friston, K.J., 2002. Distributional assumptions in voxel-based morphometry. Neuroimage 17, 1027-1030.

Savic, I., Berglund, H., 2004. Passive perception of odors and semantic circuits. Hum Brain Mapp 21, 271-278.

Savic, I., Gulyas, B., Larsson, M., Roland, P., 2000. Olfactory functions are mediated by parallel and hierarchical processing. Neuron 26, 735-745.

Savic, I., Heden-Blomqvist, E., Berglund, H., 2009. Pheromone signal transduction in humans: what can be learned from olfactory loss. Hum Brain Mapp 30, 3057-3065.

Schyns, P.G., Goldstone, R.L., Thibaut, J.P., 1998. The development of features in object concepts. Behav Brain Sci 21, 1-17; discussion 17-54.

Seubert, J., Freiherr, J., Frasnelli, J., Hummel, T., Lundstrom, J.N., 2012. Orbitofrontal Cortex and Olfactory Bulb Volume Predict Distinct Aspects of Olfactory Performance in Healthy Subjects. Cereb Cortex.

Shapiro, L.A., Ng, K.L., Kinyamu, R., Whitaker-Azmitia, P., Geisert, E.E., Blurton-Jones, M., Zhou, Q.Y., Ribak, C.E., 2007. Origin, migration and fate of newly generated neurons in the adult rodent piriform cortex. Brain Struct Funct 212, 133-148.

Sluming, V., Barrick, T., Howard, M., Cezayirli, E., Mayes, A., Roberts, N., 2002. Voxel-based morphometry reveals increased gray matter density in Broca's area in male symphony orchestra musicians. Neuroimage 17, 1613-1622.

Small, D.M., Prescott, J., 2005. Odor/taste integration and the perception of flavor. Exp Brain Res $166,345-357$.

Small, D.M., Zatorre, R.J., Dagher, A., Evans, A.C., Jones-Gotman, M., 2001. Changes in brain activity related to eating chocolate: from pleasure to aversion. Brain 124, 1720-1733.

Smejkal, V., Druga, R., Tintera, J., 2003. Olfactory activity in the human brain identified by fMRI. Bratisl Lek Listy 104, 184-188. 
Tardif, C.L., Collins, D.L., Pike, G.B., 2009. Sensitivity of voxel-based morphometry analysis to choice of imaging protocol at $3 \mathrm{~T}$. Neuroimage 44, 827-838.

Thieben, M.J., Duggins, A.J., Good, C.D., Gomes, L., Mahant, N., Richards, F., McCusker, E., Frackowiak, R.S., 2002. The distribution of structural neuropathology in pre-clinical Huntington's disease. Brain 125, 1815-1828.

Trachtenberg, J.T., Chen, B.E., Knott, G.W., Feng, G., Sanes, J.R., Welker, E., Svoboda, K., 2002. Long-term in vivo imaging of experience-dependent synaptic plasticity in adult cortex. Nature 420, 788-794.

Veyrac, A., Sacquet, J., Nguyen, V., Marien, M., Jourdan, F., Didier, A., 2009. Novelty determines the effects of olfactory enrichment on memory and neurogenesis through noradrenergic mechanisms. Neuropsychopharmacology 34, 786-795.

Walker, A.E., 1940. A cytoarchitectural study of the prefrontal area of the macaque monkey. J. Comp. Neurol. 73, 59-86.

Warnking, J., Dojat, M., Guerin-Dugue, A., Delon-Martin, C., Olympieff, S., Richard, N., Chehikian, A., Segebarth, C., 2002. fMRI retinotopic mapping--step by step. Neuroimage 17, 16651683.

Wattendorf, E., Welge-Lussen, A., Fiedler, K., Bilecen, D., Wolfensberger, M., Fuhr, P., Hummel, T., Westermann, B., 2009. Olfactory impairment predicts brain atrophy in Parkinson's disease. J Neurosci 29, 15410-15413.

Wicker, B., Keysers, C., Plailly, J., Royet, J.P., Gallese, V., Rizzolatti, G., 2003. Both of us disgusted in My insula: the common neural basis of seeing and feeling disgust. Neuron 40, 655-664.

Zatorre, R.J., Fields, R.D., Johansen-Berg, H., 2012. Plasticity in gray and white: neuroimaging changes in brain structure during learning. Nat. Neurosci. 15, 528-536.

Ziegler, G., Dahnke, R., Jancke, L., Yotter, R.A., May, A., Gaser, C., 2011. Brain structural trajectories over the adult lifespan. Hum Brain Mapp. 